\title{
Depression in Women with Recurrent Miscarriages - an Exploratory Study
}

\section{Depressão em mulheres com perdas gestacionais recorrentes - um estudo investigativo}

\author{
Ariel Cesar de Carvalho ${ }^{1}$ Michele Eugênio da Silva ${ }^{1}$ Bárbara Magueta Matos ${ }^{1}$ \\ Cassio Machado de Campos Bottino ${ }^{2}$ Anelise Riedel Abrahão ${ }^{1}$ Frederico Molina Cohrs ${ }^{3}$ \\ Sara Mota Borges Bottino ${ }^{1}$
}

${ }^{1}$ Escola Paulista de Medicina, Universidade Federal de São Paulo (EPM/UNIFESP), São Paulo, Brazil

2 Department of Psychiatry, Faculdade de Medicina da Universidade de São Paulo, São Paulo, Brazil

3 Program in Health Informatics of the Department of Health Informatics of Universidade Federal de São Paulo, UNIFESP, São Paulo, Brazil

Rev Bras Ginecol Obstet 2016;38:609-614.

\begin{abstract}
Address for correspondence Sara Mota Borges Bottino, MD, PhD, Escola Paulista de Medicina, Universidade Federal de São Paulo (EPM/ UNIFESP), Rua Borges Lagoa, 570 - Vila Clementino, 04038-000 São Paulo, Brazil (e-mail: sarabottino@uol.com.br).
\end{abstract}

\begin{abstract}
Keywords

- habitual abortion

- post partum depression

- violence against women

- mental health

- smoking

Objective To assess depression, domestic violence and the use of substances in women with recurrent miscarriages.

Methods The Abuse Assessment Screen (AAS), the Edinburgh Postnatal Depression Scale (EPDS) and the Alcohol, Smoking and Substance Involvement Screening Test (ASSIST) were used to assess violence, depression and the use of substances among women with recurrent miscarriages. The population corresponded to patients receiving prenatal care from June to August 2014. Multiple logistic regression was used to assess the multivariable relationship between depression and sociodemographic, psychosocial and medical characteristics $(p<0,10)$.

Results The prevalence of depression was of $41.3 \%$ (95\% confidence interval $[\mathrm{Cl}]$ $=28.3-55.7 \%$ ). One third of the pregnant women (32.6\%) reported emotional or physical violence, and $13 \%$ were classified as abusing or addicted to tobacco according to ASSIST. History of psychiatric diseases was associated with depression $(p=0.005)$. Violence during life demonstrated a modest association $(p=0.073)$ with depression, as well as the number of miscarriages ( $p=0.071)$.

Conclusion Depression is a frequent disease among pregnant women with recurrent miscarriages. The results of this investigation suggest that a systematic assessment of depression and its associated conditions, such as domestic violence and the use of substances, should be part of the prenatal follow-up visits for women with recurrent miscarriages.
\end{abstract}

received

March 3, 2016

accepted

November 1, 2016

published online

December 26, 2016
DOI http://dx.doi.org/

10.1055/s-0036-1597667. ISSN 0100-7203.
Copyright $\odot 2016$ by Thieme-Revinter

Publicações Ltda, Rio de Janeiro, Brazil
License terms

(c) (i) $\ominus$ (\$) 


\section{Resumo}

\author{
Palavras-chave \\ - aborto habitual \\ - depressão pós-parto \\ - violência contra a \\ mulher \\ - saúde mental \\ - hábito de fumar
}

Objetivo Avaliar a presença de depressão, violência doméstica e uso de substâncias em gestantes com história de perdas gestacionais de repetição.

Métodos Foram utilizados os instrumentos: Edinburgh Postnatal Depression Scale (EPDS), Alcohol, Smoking and Substance Involvement Screening Test (ASSIST), Abuse Assessment Screen (AAS), além de um questionário com dados sociodemográficos e clínicos elaborado pelos investigadores. As variáveis que apresentaram associação com depressão na análise bivariada $(p<0,10)$, tais como número de abortos e violência durante a vida, entraram no modelo de regressão logística.

Resultados Foram entrevistadas 46 pacientes, sendo encontrada uma prevalência de depressão de $41,3 \%$ (intervalo de confiança [IC] de $95 \%=28,3-55,7 \%$ ). Com relação à violência contra a mulher, um terço das gestantes $(32,6 \%)$ foi vítima de violência emocional ou física pelo seu parceiro ou por alguém próximo a elas. O abuso e/ou dependência de tabaco estava presente em $13 \%$ das gestantes, segundo o ASSIST. Na análise bivariada, observou-se uma associação significativa entre histórico de doença psiquiátrica e depressão em mulheres com abortamento de repetição $(p=0,005)$. Observamos também uma tendência de associação entre depressão, número de abortos $(p=0,071)$ e histórico de violência durante a vida $(p=0,073)$.

Conclusão Depressão é uma doença frequente entre as gestantes com abortamento de repetição. A sobreposição entre depressão, violência doméstica e uso de substâncias aponta para a necessidade do rastreio sistemático dessas condições no pré-natal de gestantes com perdas gestacionais de repetição.

\section{Introduction}

Habitual or recurrent miscarriage is defined as the spontaneous and consecutive interruption of 3 or more pregnancies before the 22nd week. Recurrent miscarriages occur in up to $5 \%$ of women in reproductive age, with devastating effects on their lives and those of their families. ${ }^{1}$ The most frequent causes associated with recurrent miscarriages are of genetic, anatomic, hormonal and immunological nature. However, half of the cases are classified as 'unknown causes'. The assessment and followup of women with recurrent miscarriages represents a challenge for the clinical practice, especially due to the diversity of factors involved in the etiology, as well as the repercussions in the mental health of the patients and their families.

Recurrent miscarriages are among the repercussions of the violence perpetrated by close partners, in addition to undesired pregnancy, preterm birth, low weight upon birth, neonatal death, depression, anxiety and, as a consequence of the latter, alcohol and drug abuse. ${ }^{2}$ In a study performed in Brazil with women under prenatal care, the prevalence of psychological and physical violence was of $19.1 \%$ and $6.5 \%$ (Campinas, SP; $n=1379$ ). In this sample, violence was associated with major obstetric repercussions, such as ruptured membranes, urinary tract infections, cephalalgia and risky sexual behaviors. ${ }^{3}$

Violence perpetrated by intimate partners during pregnancy is associated to depression, to an increase in the use of alcohol, tobacco and other drugs (ATOD), to the reduction in the chances of interrupting the use of such substances, and to the delay in the search for prenatal care. ${ }^{4}$ Studies have suggested that pregnancy could be a factor of protection against domestic violence, with a decrease or interruption in the episodes of abuse. $^{2,5}$ However, other studies indicate that there are no changes in the abusive pattern during pregnancy, with the possibility of exacerbation in severity and frequency, or even the beginning of aggressions during pregnancy. ${ }^{2}$ Domestic violence, stressful events and the absence of social support are risk factors for depression during pregnancy. ${ }^{6}$ Depression and the use of alcohol during pregnancy increase the risks of negative outcomes for the mother and the baby. ${ }^{7}$ This study aimed at assessing the presence of depression, domestic violence and the use of substances in pregnant women with a history of recurrent miscarriages.

\section{Methodology}

This is a crossectional epidemiological study, performed at the Recurrent Miscarriage Outpatient Facilities of Casa de Saúde da Mulher Domingos Deláscio, at Universidade Federal de São Paulo (UNIFESP), located in the southern area of São Paulo. Women in the public healthcare system with a history of two or more consecutive miscarriages are referred to this center. The study population corresponded to all patients with visits scheduled during the period of June to August 2014.

The patients responded to the questionnaires in a comfortable and reserved space after the visit with the obstetrician. Whenever necessary, the questions were read aloud by Medicine and Nursing students. From the 80 selected patients, 
46 (57.5\%) were interviewed, 20 (23\%) did not accept to participate, for lack of time or difficulty in scheduling the interview on another date, mainly due to the distance from their homes, and 14 patients (17.5\%) were not interviewed after the obstetric visit, and were not found after 2 or more telephone contacts. There were no meaningful differences in terms of sociodemographic characteristics (age, schooling and income) among the participants and the non-participants of the study. This study was approved by the Ethics and Research Committee of UNIFESP. All patients signed an informed consent form. Additionally, the research was performed in accordance with the Helsinki Declaration, revised in 2008.

The questionnaire was prepared to recompile sociodemographic and clinical information, such as: age, marital status (single and common-law marriage), occupation (work at home or outside of it), education (years of schooling), family income (minimum wage per capita), number of miscarriages, social support (considered as partner and/or family support) and history of psychiatric diseases. Instruments that are specific for tracking violence, depression and the use of substances in the pregnant women population were translated and adapted to be applied in the Brazilian context: the Abuse Assessment Screen (AAS), the Edinburgh Postnatal Depression Scale (EPDS) and the Alcohol, Smoking and Substance Involvement Screening Test (ASSIST).

The AAS is made up of questions that assess the nature of the violence (emotional, physical, and sexual), its severity, frequency, and the perpetrator in the last year, during pregnancy and throughout life. ${ }^{8,9}$ The EPDS contains ten items that assess the presence and intensity of the depressive symptoms over the past seven days. We used the cutoff point of 10 , which has a sensitivity of $86.4 \%$ and a specificity of $91.1 \%$ for depressive disorder during pregnancy and postnatally. ${ }^{10}$ The ASSIST tracks the use of alcohol, tobacco and other psychoactive substances, over the past three months and throughout life. The cases are ranked based on a score according to occasional use, abuse and dependence. ${ }^{11}$

The descriptive statistics of the sociodemographic variables and the results of the scales (average [A], standard deviation [SD], 95\% confidence interval [CI] and percentage of frequencies) were calculated. We used Pearson's chisquare or Fisher's Exact Test to compare the frequencies of the categorical variables (univariate analysis). The comparison of the continuous variables scores was made using Student's $t$-test.

We used logistic regression (enter method) to assess the associations among sociodemographic, medical (personal and family history) and depression variables. The variable number of miscarriages was grouped as: two miscarriages, and three or more miscarriages. The selection criteria to be included in the multivariate analysis considered variables that, at the univariate analysis, presented $p$ values lower than 0.10 . The variable of psychiatric history was not included in the multivariate analysis because all women with depression presented psychiatric history. The Reasons of Chance were calculated, with $95 \%$ CIs. The study data was analyzed with the SPSS software, version 16 for Windows (Statistical Package for the Social Sciences Inc., Chicago, USA).

\section{Results}

Among the 46 patients that participated in the study, 40 (87\%) were pregnant, with an average pregnancy time of 21 weeks $(S D=9)$. The age of the patients ranged between 18 and 42 years $(A=31 ; S D=5.9)$. The majority lived with their partner $(89.1 \%)$, worked paying jobs outside their homes (56.5\%), and had a family income higher than 1.5 minimum wage (60.8\%). Regarding ethnicity, they referred to themselves as black or brown (54.3\%). As for education, the average was of 9.8 years of schooling $(S D=3)$, and $75 \%$ of the patients had 8 or more years of schooling. Regarding social support, $10.9 \%$ informed that they do not have social support from their partners and/or families.

History of psychiatric diseases was present in $10.9 \%$ of the patients, and $13 \%$ had records of tobacco abuse or dependence. When it comes to violence against women, one third of the pregnant women (32.6\%) were victims of emotional or physical violence perpetrated by a partner or by someone close to them. Episodes of violence occurred over the past year for $6.5 \%$ of the women, and 1 of them, in addition to sexual abuse, also suffered from violence during the current pregnancy. The prevalence of depression at these recurrent miscarriage outpatient facilities was of $41.3 \%$ (95\% CI $=28.3-55.7 \%$ ). The relationship between depression and the multiple variables is demonstrated in - Table $\mathbf{1}$.

A significant association between the history of psychiatric diseases and depression in women with recurrent miscarriages $(p=0.005)$ was observed. We also noticed a tendency of association among depression, number of miscarriages $(p=0.071)$ and history of violence during life $(p=0.073)$. The variables that presented association with depression in the bivariate analysis $(p<0.10)$, such as number of miscarriages and violence during life, were included in the logistic regression model (-Table 2 ).

History of violence during life increased the risk of depression 3-fold in this sample; however, this association was not statistically significant $(p=0.089)$.

\section{Discussion}

The most important finding in this study was the high prevalence of depression in pregnant women with recurrent miscarriages: $41.3 \%$ (95\% $\mathrm{CI}=28.3-55.7 \%)$. This result suggests that this disorder is very common in women who suffer from recurrent interruptions of their pregnancies. The factors that were associated with depression in women with recurrent miscarriages were: history of psychiatric diseases, violence throughout life, and the number of miscarriages. Though history of psychiatric disorders and violence are known risk factors for depression in normal pregnancies, both in international and national studies, ${ }^{12-14}$ the risk factors for depression in women with high-risk pregnancies are still under study. 
612 Depression in Women with Recurrent Miscarriages Carvalho et al.

Table 1 Sociodemographic and clinical characteristics, and depression in women with recurrent miscarriages

\begin{tabular}{|c|c|c|c|c|c|}
\hline \multirow[t]{2}{*}{ Variables } & \multicolumn{2}{|c|}{ With depression } & \multicolumn{2}{|c|}{ Without depression } & \multirow[t]{2}{*}{$p$} \\
\hline & $\mathbf{N}$ & $\%$ & $\mathrm{~N}$ & $\%$ & \\
\hline \multicolumn{6}{|l|}{ Age group } \\
\hline 18 to 30 years old & 9 & $39.1 \%$ & 14 & $60.9 \%$ & \multirow[t]{2}{*}{0.765} \\
\hline 30 years old or more & 10 & 43.5 & 13 & $56.5 \%$ & \\
\hline \multicolumn{6}{|l|}{ Marital status } \\
\hline Single & 2 & $4.4 \%$ & 3 & $6.5 \%$ & \multirow[t]{2}{*}{0.950} \\
\hline Common-law marriage & 17 & $36.9 \%$ & 24 & $52.2 \%$ & \\
\hline \multicolumn{6}{|l|}{ Occupation } \\
\hline Does not work outside the home & 6 & $14.3 \%$ & 10 & $23.8 \%$ & \multirow[t]{2}{*}{0.758} \\
\hline Works outside the home & 11 & $26.2 \%$ & 15 & $25.7 \%$ & \\
\hline \multicolumn{6}{|l|}{ Education } \\
\hline 8 years or more of schooling & 4 & $28.6 \%$ & 10 & $71.4 \%$ & \multirow[t]{2}{*}{0.246} \\
\hline More than 8 years of schooling & 15 & $46.9 \%$ & 17 & $53.1 \%$ & \\
\hline \multicolumn{6}{|l|}{ Family income } \\
\hline$<1.5$ minimum wage & 4 & $10 \%$ & 3 & $7.5 \%$ & \multirow[t]{2}{*}{0.477} \\
\hline$>1.5$ minimum wage & 14 & $3.5 \%$ & 19 & $47.5 \%$ & \\
\hline \multicolumn{6}{|l|}{ Number of miscarriages } \\
\hline 2 & 11 & $23.9 \%$ & 11 & $23.9 \%$ & \multirow[t]{6}{*}{$0.071^{*}$} \\
\hline 3 & 2 & $4.3 \%$ & 10 & $21.7 \%$ & \\
\hline 4 & 3 & $6.5 \%$ & 4 & $8.7 \%$ & \\
\hline 5 & 2 & $10.5 \%$ & 0 & $0 \%$ & \\
\hline 6 & 0 & $0 \%$ & 2 & $4.3 \%$ & \\
\hline 8 & 1 & $2.2 \%$ & 0 & $0 \%$ & \\
\hline \multicolumn{6}{|l|}{ Social support during pregnancy } \\
\hline Yes & 16 & $34.8 \%$ & 25 & $54.3 \%$ & \multirow[t]{2}{*}{0.368} \\
\hline No & 3 & $6.5 \%$ & 2 & $4.4 \%$ & \\
\hline \multicolumn{6}{|l|}{ History of psychiatric diseases } \\
\hline Yes & 5 & $10.9 \%$ & 0 & $0 \%$ & \multirow[t]{2}{*}{$0.005^{*}$} \\
\hline No & 14 & $30.4 \%$ & 27 & $58.7 \%$ & \\
\hline \multicolumn{6}{|l|}{ Tobacco abuse/dependence } \\
\hline Positive & 4 & $8.7 \%$ & 2 & $4.3 \%$ & \multirow[t]{2}{*}{0.176} \\
\hline Negative & 15 & $32.6 \%$ & 25 & $54.4 \%$ & \\
\hline \multicolumn{6}{|l|}{ History of violence } \\
\hline Yes & 9 & $19.6 \%$ & 6 & $13 \%$ & \multirow[t]{2}{*}{$0.073^{*}$} \\
\hline No & 10 & $21.7 \%$ & 21 & $45.7 \%$ & \\
\hline \multicolumn{6}{|l|}{ Violence over the past year } \\
\hline Yes & 2 & $4.4 \%$ & 1 & $2.2 \%$ & 0.356 \\
\hline No & 17 & $36.9 \%$ & 26 & $56.5 \%$ & \\
\hline Violence during pregnancy & & & & & \\
\hline Yes & 1 & $2.2 \%$ & 0 & $0 \%$ & 0.228 \\
\hline No & 18 & $29.1 \%$ & 27 & $58.7 \%$ & \\
\hline
\end{tabular}

${ }^{*}$ Modest association $(p=0.073)$, but no statistical significance $(p<0.05)$. 
Table 2 Multivariate analysis of the factors associated with depression

\begin{tabular}{|c|c|c|}
\hline Variables & OR & $95 \% \mathrm{Cl}$ \\
\hline \multicolumn{3}{|l|}{ History of violence } \\
\hline No & 0 & \\
\hline Yes & 3.074 & $0.85-11.2$ \\
\hline \multicolumn{3}{|c|}{ Number of miscarriages } \\
\hline $\begin{array}{l}\text { Three or more } \\
\text { miscarriages }\end{array}$ & 0 & \\
\hline Two miscarriages & 0.52 & $0.15-1.78$ \\
\hline
\end{tabular}

Abbreviations: $\mathrm{Cl}$, confidence interval; OR, odds ratio.

The study has some limitations, such as the scope of the sample and the selection of participants that came from a single outpatient facility of the Brazilian Unified Healthcare System (SUS, in the Portuguese acronym). The study was performed transversely, and it was not possible to establish a temporal relationship between the study risk factors and depression during pregnancy. On the other hand, there is a need for an exploratory study aimed at assessing the association of other relevant factors to prenatally track the pregnant women considered of high-risk for fetal losses, and also for the "loss" of their mental health.

The prevalence of depression found in this study was: $41.3 \%$, higher than that found for low-risk pregnancies, which is estimated at 15 to $29 \%$ in several international and national studies. ${ }^{10,15,16}$ This research corroborates the results of the Brazilian study conducted by Francisco et al, ${ }^{17}$ which identified twice as much depression in patients with recurrent miscarriages in comparison with normal pregnancies. The psychological impact of these losses, and having to live with the insecurity and threat of a new miscarriage may increase the vulnerability and frequency of psychiatric symptoms, which results in an increase in the prevalence of disorders related to depression and anxiety in this population. ${ }^{18,19}$ Therefore, tracking depression and its risk factors should be part of the routine in the prenatal visits of women with recurrent miscarriages.

In this sample, we found a higher frequency of history of violence in women with depression, though it did not have statistical significance $(p<0.07)$. It is possible to suppose that this association did not have statistical significance due to the scope of the sample. Studies on violence against women indicate pregnancy as a condition that may determine the beginning of aggressions, with an increase in their severity and frequency, or continuity of the abusive pattern. ${ }^{6,20}$ In a study performed in Brazil with women that were under prenatal care, the prevalence of psychological and physical violence was of $19.1 \%$ and $6.5 \%{ }^{3}$ We identified a single case of violence during the current pregnancy, which, albeit illustrative, evidences the importance of tracking violence during pregnancy, considering the serious consequences of this situation for the health of these women, such as hemorrhages and the interruption of pregnancy. ${ }^{21}$ Aditionally, there are damages to the child's health, such as an increase in the risk of perinatal death, low weight and prematurity. ${ }^{22}$ Studies with larger samples are necessary to assess the repercussions of violence, especially in women with recurrent miscarriages.

With regard to the use of psychoactive substances during pregnancy, $13 \%$ of the pregnant women were ranked in the group of abuse and/or dependence of tobacco by the ASSIST. In general, this frequency is similar to the female population number, at around $13.1 \%$, according to data by the Brazilian Institute of Geography and Statistics (IBGE, in the Portuguese acronym), ${ }^{23}$ and also based on Brazilian studies that assessed the use of tobacco during pregnancy. ${ }^{24,25}$ These numbers indicate that, though women have high-risk pregnancies, such as in the case of recurrent miscarriages, the number of women who use tobacco brings great concern. The use of tobacco increases the rate of occurrence of risk factors for the pregnancy, that is, it may trigger a higher number of complications, such as placenta previa, the premature rupture of membranes, the premature separation of the placenta, antepartum hemorrhage, ectopic pregnancy, restricted intrauterine growth, and low weigh upon birth, as well as impairment in the child's physical development. ${ }^{24}$ This result indicates the importance of approaching this theme during prenatal visits, which does not occur in a satisfactory way, as evidenced by the literature, which reveals that only 66 to $68 \%$ of the pregnant women discussed the use of tobacco with their doctors, and did not have sufficient information on the impact of smoking on their pregnancies. ${ }^{24,26}$

Women who had four or more miscarriages represented $20 \%$ of the study. In the bivariate analysis, we noticed a tendency of association between the number of miscarriages and depression, which was not confirmed in the multivariate analysis. The literature has demonstrated the association between recurrent miscarriages and depression; ${ }^{27}$ however, there are no studies that assess the relation between the number of miscarriages and depression. Considering the exploratory character of this research, the importance of the number of miscarriages for depression needs to be investigated in further studies.

The analysis of data on depression, domestic violence and use of substances indicates the need for a systematic tracking of these conditions during the follow-up of prenatal visits of women with recurrent miscarriages.

\section{Acknowledgments}

We thank the employees, nurses, doctors and resident doctors from Casa de Saúde da Mulher Domingos Deláscio, Universidade Federal de São Paulo, for the support in the data collection stage of our research. And we thank Marcos Cunha Aquino for his support in preparing the English text. 


\section{References}

1 Practice Committee of American Society for Reproductive Medicine. Definitions of infertility and recurrent pregnancy loss: a committee opinion. Fertil Steril 2013;99(1):63

2 Gazmararian JA, Lazorick S, Spitz AM, Ballard TJ, Saltzman LE, Marks JS. Prevalence of violence against pregnant women. JAMA 1996;275(24):1915-1920

3 Audi CAF, Segall-Corrêa AM, Santiago SM, Pérez-Escamilla R. Adverse health events associated with domestic violence during pregnancy among Brazilian women. Midwifery 2012;28(4):356-361

4 Plichta SB. Intimate partner violence and physical health consequences: policy and practice implications. J Interpers Violence 2004;19(11):1296-1323

5 Sarkar NN. The impact of intimate partner violence on women's reproductive health and pregnancy outcome. J Obstet Gynaecol 2008;28(3):266-271

6 Lancaster CA, Gold KJ, Flynn HA, Yoo H, Marcus SM, Davis MM. Risk factors for depressive symptoms during pregnancy: a systematic review. Am J Obstet Gynecol 2010;202(1):5-14

7 Brasil. Ministério da Saúde. Secretaria de Atenção à Saúde. Departamento de Ações Programáticas Estratégicas. Pré-natal e puerpério: atenção qualificada e humanizada: manual técnico. Brasília (DF): Ministério da Saúde; 2006

8 Norton LB, Peipert JF, Zierler S, Lima B, Hume L. Battering in pregnancy: an assessment of two screening methods. Obstet Gynecol 1995;85(3):321-325

9 Reichenheim ME, Moraes CL, Hasselmann MH. Semantic equivalence of the Portuguese version of the Abuse Assessment Screen tool used for the screening of violence against pregnant women. Rev Saude Publica 2000;34(6):610-616

10 Figueira P, Correa H, Malloy-Diniz L, Romano-Silva MA. Edinburgh Postnatal Depression Scale for screening in the public health system. Rev Saude Publica 2009;43( Supl (Suppl 1):79-84

11 Henrique IFS, De Micheli D, Lacerda RB, Lacerda LA, Formigoni MLOS. Validation of the Brazilian version of Alcohol, Smoking and Substance Involvement Screening Test (ASSIST). Rev Assoc Med Bras (1992) 2004;50(2):199-206

12 Gulseren L, Erol A, Gulseren S, Kuey L, Kilic B, Ergor G. From antepartum to postpartum: a prospective study on the prevalence of peripartum depression in a semiurban Turkish community. J Reprod Med 2006;51(12):955-960

13 Rich-Edwards JW, Kleinman K, Abrams A, et al. Sociodemographic predictors of antenatal and postpartum depressive symptoms among women in a medical group practice. J Epidemiol Community Health 2006;60(3):221-227
14 Pereira PK, Lovisi GM, Pilowsky DL, Lima LA, Legay LF. Depression during pregnancy: prevalence and risk factors among women attending a public health clinic in Rio de Janeiro, Brazil. Cad Saude Publica 2009;25(12):2725-2736

15 Vesga-López O, Blanco C, Keyes K, Olfson M, Grant BF, Hasin DS. Psychiatric disorders in pregnant and postpartum women in the United States. Arch Gen Psychiatry 2008;65(7):805-815

16 Santos IS, Matijasevich A, Tavares BF, et al. Validation of the Edinburgh Postnatal Depression Scale (EPDS) in a sample of mothers from the 2004 Pelotas Birth Cohort Study. Cad Saude Publica 2007;23(11):2577-2588

17 Francisco MdeF, Mattar R, Bortoletti FF, Nakamura MU. [Sexuality and depression among pregnant women with recurrent spontaneous abortion]. Rev Bras Ginecol Obstet 2014;36(4):152-156

18 Geller PA, Kerns D, Klier CM. Anxiety following miscarriage and the subsequent pregnancy: a review of the literature and future directions. J Psychosom Res 2004;56(1):35-45

19 Tsartsara E, Johnson MP. The impact of miscarriage on women's pregnancy-specific anxiety and feelings of prenatal maternalfetal attachment during the course of a subsequent pregnancy: an exploratory follow-up study. J Psychosom Obstet Gynaecol 2006; 27(3):173-182

20 Martin SL, Harris-Britt A, Li Y, Moracco KE, Kupper LL, Campbell JC. Changes in intimate partner violence during pregnancy. J Fam Violence 2004;19(4):201-210

21 Watts C, Zimmerman C. Violence against women: global scope and magnitude. Lancet 2002;359(9313):1232-1237

22 Coker AL, Sanderson M, Dong B. Partner violence during pregnancy and risk of adverse pregnancy outcomes. Paediatr Perinat Epidemiol 2004;18(4):260-269

23 Instituto Brasileiro de Geografia e Estatística. Pesquisa Nacional por Amostra de Domicílios: Tabagismo 2008. Rio de Janeiro: IBGE; 2009

24 da Motta GdeC, Echer IC, Lucena AdeF. Factors associated with smoking in pregnancy. Rev Lat Am Enfermagem 2010;18(4): 809-815

25 Rocha RS, Bezerra SC, Lima JWO, Costa FdaS. Consumption of medications, alcohol and smoking in pregnancy and assessment of teratogenic risks. Rev Gaucha Enferm 2013;34(2):37-45

26 Králíková E, Bajerová J, Raslová N, Rames J, Himmerová V. Smoking and pregnancy: prevalence, knowledge, anthropometry, risk communication. Prague Med Rep 2005;106(2):195-200

27 Toffol E, Koponen P, Partonen T. Miscarriage and mental health: results of two population-based studies. Psychiatry Res 2013; 205(1-2):151-158 